\title{
THE FLORENCE BAPTISTERY: 3-D SURVEY AS A KNOWLEDGE TOOL FOR HISTORICAL AND STRUCTURAL INVESTIGATIONS
}

\author{
G. Tucci*, V. Bonora, L. Fiorini, A. Conti \\ GECO Lab., University of Florence - DICEA Dept., Via P.A. Micheli 8, Florence \\ *grazia.tucci@unifi.it
}

Commission VI, WG VI/4

KEY WORDS : Laser scanning, Cultural heritage, Comparison, Orthoimages

\begin{abstract}
:
The Baptistery of San Giovanni is one of the most important pieces of architecture in Florence. It is an octagonal building, encrusted with marble both internally and externally (including the pyramidal roof) and covered inside by a magnificent dome with sparkling gold mosaics. During Dante's time, it appeared much older than the other monuments, so its origins were considered as hailing straight from Florence's most remote and my thical history. Even though we have much more data now, scholars still disagree over the interpretations on the origin and construction sequence of the monument.

Survey has always been considered a main instrument for understanding historical architecture, mostly from constructional and structural points of view. During the last century, the Baptistery was surveyed using both traditional techniques and the most up-todate instruments available at the time, such as topography, close-range photogrammetry and laser scanning. So, a review of those early applications, even if partial or isolated, can significantly attest to the state of the art and evolution of survey techniques.

During recent years, the Opera di Santa Maria del Fiore promoted new research and a wide range of diagnostic investigations aimed at acquiring greater knowledge of the monument in anticipation of the cleaning and restoration of the outer wall surfaces during 2015.

Among this research, GeCo Lab carried out a new systematic and complete laser scanner survey of the whole Baptistery, acquiring data for the more inaccessible parts that were given little attention during other survey campaigns.

First of all, the paper analyses recent contributions given by instrumental surveys in advancing knowledge of the building, with references to the cutting-edge techniques and measurement tools used at the time.

Then, it describes the new survey campaign, illustrating the approach followed in the planning, data acquisition and data elaboration phases; finally, it gives examples of some interpretations of the structure stemming from the new acquisitions.
\end{abstract}

\section{INTRODUCTION}

Every building is testimony of the spatial conception of its time, and, at the same time, a distinct - at times unique - solution to a construction problem. As a consequence, especially for the most important architectures that are furthest from current concepts, it is the building itself that provides the most reliable (and the only incontrovertible) document of the historical events that led to its present-day conformation.

Hence, as of the Renaissance in particular, surveys have been recognized as the most incisive form of knowledge of the built environment and have been adopted as an essential element in architects' training.

Obviously, the painstaking activity of understanding of the basic components of a building, to then be simplified into graphical output summing up the most significant elements, is an operation that is not carried out just once and that is the end of it. Instead, like every critical discourse, each time they are the expression of different needs and requests. In the history of the depictions of all large buildings such as the Baptistery, we can see both the evolution of the graphical representations and of the drawing techniques, which, in turn, also changed depending on how they could be printed. The reproduction techniques available (line, half-tone, colour, photographic...) condition the selection of the elements to survey beforehand. In the same way, the print formats inevitably end up determining the metric scale to be used in making the graphics, and, therefore, ultimately the minimum level of detail that it is worth devoting attention to during the costly fieldwork phase.

Another determining aspect consists of which measurement tools are available: the tools used by surveyors remained almost unchanged for centuries. Tellingly, they were the same as those used by the builders, amongst which longimeters, plumb lines, spirit levels and few others. It is only since the end of the nineteenth century that survey instruments have been aimed at architecture, in what was initially a slow process, limited to a few exemplary cases (Balletti, 2015).

The Baptistery of San Giovanni is one of the earliest case studies using the most up-to-date survey techniques which gradually became available. Despite being sporadic, these first applications show right from the start how scholars increasingly went on to consider surveys - and measurement in itself - as a tool for interpreting the building, in the attempt to define an 
objective description that can thus settle the controversies that have always accompanied its interpretations.

The following section documents how in the past this illustrious piece of architecture was often considered worthy of surveys with cutting-edge technologies, therefore a review of its surveys matches up with the evolution of tools and techniques.

Then the paper presents the recent GeCo Lab experience, firstly analy sing the preliminary assessment made in order to plan both the work on the field and the following data elaboration. After that, it briefly describes the data acquired by laser scanning and the graphical output we obtained. Finally, it presents some examples of interpretations of the building which have been possible thanks to the new digital survey.

\section{PREVIOUS EXPERIENCES OF INSTRUMENTAL SURVEYS}

In preparation for our new survey, we re-examined the main surveys from the past century, focussing our attention on those based on first-hand measurements which were not reelaborations of drawings by others. Moreover, considering that our task was to survey the parts above ground only, surveys of the subterraneous portions and the important archaeological digs were not taken into consideration, even though we are aware of their essential contribution to clarifying the history of the construction and dating of the Baptistery.

The documents analysed are summed up in Table 1 , in chronological order; many bear witness to important partnerships between scholars of the building and surveyors from the world of topography or photogrammetry. Technological evolution and new tools make it quicker and less expensive to measure points: in the $1940 \mathrm{~s}$, to describe the geometry of the vault just one profile was analy sed, and just six points measured, with the demanding procedures required by forward intersection. (Sabatini, 1943) At the end of the 1980s, the availability of a laser pointer to spot the point to measure made it easier to measure all the groins (Aminti, 1996) highlighting the irregularities of the different sides and therefore gaining greater knowledge of the structure. Finally, at the end of the 1990s, it was possible to study the whole of the dome and no longer its geometric discontinuity only. Both wellconsolidated photogrammetric techniques (Ferri, 2004) and newly tested scanning systems were used (Caroti, 2004).

In the period under consideration, instrumental surveys alternated with direct surveys, which were always significant (albeit never totally exhaustive) owing to the amount of graphical output illustrating the overall conformation of the building compared to the limited number of profiles described before (Pietramellara, 1973; Corsucci, 1996; Giovannini, 1996) Comparison of the drawings produced with the new survey highlights on one hand the appreciable level of detail of the representations, while on the other showing the limits of direct measurement:

- in the survey coordinated by Pietramellara the floor plans are substantially correct in contrast to the significant errors in the section, in spite of the difficulties in measuring such remarkable heights with traditional tools (Pietramellara, 1973);

- upon publication of the measurements, Corsucci, Dalzocchio e Pedini (Corsucci, 1996) highlight a growing attention towards survey metadata, namely the information that can be used to reconstruct and, if necessary, verify the survey itself;

- P. Giovannini (Giovannini, 1996) makes both direct and instrumental measurements. In this case too, the results are evident in the depictions of the backgrounds of the section, in particular the cladding of the foreshortened walls. The representations were correct when stemming from photogrammetric plotting and inevitably "deformed" when rely ing on the direct measurements alone.

\begin{tabular}{|c|c|c|c|c|}
\hline Year & Author & Subject of the survey & Technology adopted & Tools \\
\hline 1943 & R. Sabatini & Profile of a rib (6 points) & $\begin{array}{l}\text { Topography, forward } \\
\text { intersection }\end{array}$ & Zeiss theodolite \\
\hline 1973 & C. Pietramellara & Floor plans and section & $\begin{array}{l}\text { Not described (direct } \\
\text { survey) }\end{array}$ & Direct measurement tools \\
\hline 1981 & $\begin{array}{l}\text { S. Corsucci, M. } \\
\text { Dalzocchio, L. Pedini }\end{array}$ & Floor plans & Direct survey & Direct measurement tools \\
\hline 1989 & P. Aminti & Rib profile (160 points) & $\begin{array}{l}\text { Topography, forward } \\
\text { intersection }\end{array}$ & $\begin{array}{l}\text { G.T.S. system Galileo Siscam } \\
\text { (two stations, one with a laser } \\
\text { pointer) }\end{array}$ \\
\hline$\sim 1990$ & L. Ippolito & Internal elevation & Stereophotogrammetry & \\
\hline $\begin{array}{l}1990- \\
1995\end{array}$ & P. Giovannini & Floor plan, section, details & Direct survey & Direct measurement tools \\
\hline 1995 & L. Giorgi & $\begin{array}{l}\text { Rib profile, diagonal } \\
\text { section (partial) }\end{array}$ & $\begin{array}{l}\text { Topography, forward } \\
\text { intersection }\end{array}$ & $\begin{array}{l}\text { G.T.S. system Galileo Siscam } \\
\text { (two stations, one with a laser } \\
\text { pointer) }\end{array}$ \\
\hline 1998 & W. Ferri & $\begin{array}{l}\text { Plan of the dome from } \\
\text { below, dome segment } \\
\text { profiles }\end{array}$ & Stereophotogrammetry & Wild P 31/45 mm camera \\
\hline 1999 & G. Caroti, G. Fangi & $\begin{array}{l}\text { Dome intrados }(12,000 \\
\text { points })\end{array}$ & Laser scan - Topography & $\begin{array}{l}\text { MDL Quarryman Ace300, } \\
\text { Topcon GTP1002 reflectorless }\end{array}$ \\
\hline
\end{tabular}

Table 1. A summary of previous metric studies on the Baptistery 
By examining these experiences as a whole, it can be observed how the scholars, who commissioned, or performed themselves, increasingly accurate analyses, agreed that the hypotheses on the history, building techniques and statics of the building could no longer be separate from the evidence deriving from in-depth metric and geometric knowledge as well as other diagnostic analy ses of the Baptistery.

Besides, it is known that investigations in general, and surveys in particular, require a lot of time, both on the field and to process the data and make the graphical output; each of the experiences described best used the technologies available, optimizing the results in proportion to the amount of work needed to obtain them.

\section{THE NEW SURVEY: PRELIMINARY CONS IDERATIONS AND WORKFLOW PLANNING}

The aim of the new survey was to acquire all the above-ground surfaces of the Baptistery: in particular, in addition to all the plans (of the roofs as well) and the sections already represented in previous surveys, an additional two sections were made as well as all the façades.

Numerous survey experiences have been made in which the geometry was recorded with 3D scans and the texture documented using images oriented with respect to the 3D model (Guarnieri, 2006). Instead, for the survey of the Baptistery described here we preferred to use a scanning system with integrated photographic camera. Below is a presentation of some preliminary considerations which justify that choice. There is also a description of the workflow followed to create the required orthoimages. This was then integrated by vectorization of the section profiles and the main architectural elements.

\subsection{Orthoimages production: photogrammetric vs TLS + camera based methods}

3.1.1 Photogrammetric method: As is known, orthographic images, that is, graphics with photographic contents and a uniform scale, with perspective distortion removed on the basis of a 3D model of the object, and lens and sensor distortion removed on the basis of empirical or physical models (Remondino, 2006), can be produced by photogrammetric means. The process requires that images and 3D model are oriented in the same reference system. It consists of:

1. transforming the position of image points to their object position (DDEM, Dense Digital Elevation Model), or

2. transforming the position of each object point (DDEM) to its image point (Jauregui, 2000).

3.1.2 TLS +camera based method: If a laser scanner with an associated or integrated photographic camera is available, it is possible to produce orthophoto-like images by associating chromatic and geometric data, on the basis of the TLS+camera system calibration information, therefore rendering orthogonal views of the model.

This last phase can be performed both by using the point model and a textured mesh. The advantage of the first solution is its rapidity, as it does not require triangulation of the point model.
However, in this case the colour data are memorized at the same sampling rate as the scanning. Namely, every measured point is associated with a single colour, from a sampling of the photographic image in question.

Instead, when a mesh surface is calculated from a point model, the available methods for storing colour are (Ranzuglia, 2012):

- per vertex, with various kinds of interpolations to define the colour of the various faces, or

- as texture (assuming a parameterization), which means the whole resolution of the photographic image can be used, often also in order to preserve colour information on simplified meshes, which are therefore easy to handle but at the same time give an effective visualization. (Cignoni, 1998)

3.1.3 Our choice: In the case of the Baptistery it was necessary to produce high-resolution orthoimages to document the current state of the internal and external facings and support the investigations and recently concluded cleaning and restoration works. The quite short amount of time available (the on-site acquisitions were finished in 15 days) meant it was preferable to make orthoimages from the point model acquired by TLS since for achieving our task both photogrammetric process and mesh elaboration seemed to be excessively time consuming. A photogrammetric survey was performed for highresolution documentation of the marble inlays in the frieze in the rectangular apse. Images were taken from the scaffolding which had been put up in the meantime. The $\mathrm{Z}+\mathrm{F}$ 5010C (Zoeller+Froelich, 2015) scanner was used, which acquires geometry and photographs at the same time, thanks to an integrated onboard camera mounted on the opposite side from the rotating mirror.

\subsection{Color data acquisition by TLS}

Various scanner models can record photographic information too thanks to an externally fixed camera (with known mounting and calibration information) or a factory-calibrated internal camera. It is also possible to take photos with a DSLR camera and a Nodal Ninja support to set up the lens nodal point coinciding with the scan origin. In the last case the panorama elaboration and the texture mapping have to be done manually, which is a significantly time-consuming process.

The $\mathrm{Z}+\mathrm{F}$ system takes 42 images that are stitched and blended together in a panorama. In our experience, the solution adopted by $\mathrm{Z}+\mathrm{F}$ produces excellent results which are not affected by the small calibration residual owing to the eccentricity between the scanner origin and the camera origin, producing a small shift of the image with respect to the $3 \mathrm{D}$ data.

The unit can capture High Dynamic Range (HDR) imagery, a useful technique for taking well-exposed photographs in challenging conditions, as it takes a set of bracketed exposures. Different algorithms are used to combine pixels from different exposures in a final HDR composite. Since it is not possible to directly display an HDR image on a screen (with 8-bit gamut), a tone mapping process was performed to compress the high dynamic range radiance into a low dynamic range gamut (Szeliski, 2010). 
Unlike other scanners that allow work on an HDR image in JXR format (HDS P40 by Leica Geosystems), Z+F saves the tonemapped panorama in a JPG file, with a resolution related to the scan resolution that has been set up: the RGB resolution therefore corresponds to the geometric one. The "Super High" scan resolution, preferably adopted in the project, generates a range map made of 20,000 pixels $1360^{\circ}$ and the corresponding panorama measures 20,000 pixels.

\subsection{Planning the 3D scans}

The scan resolution is generally set depending on the minimum detail to be documented - in turn depending on the reproduction scale (2D or 3D) and/or uses of the models produced.

In this case we had to consider geometric and photographic resolution at the same time, the first expressed with the angle between two successive points and the second with the size of the GSD.

The scans were planned according to a regular acquisition schema, both around and inside the Baptistery. The acquisition positions were defined so as to "frame" significant portions of the object and guarantee complete documentation of the surfaces. Therefore, for almost all the scans we can consider the portion of surface in question to be found at a minimum/maximum distance of: between $13 \mathrm{~m}$ and $26 \mathrm{~m}$. The acquisition parameters were assessed and then planned with respect to that interval.

In the scanner used, the geometric resolution can only be set for preset intervals (Normal, High, Super High, etc). With the exception of some detailed scans from closer-up and the scan windows taken from the buildings around the Baptistery to document the roofs, the resolution adopted was "Super High", corresponding to a distance between consecutive points of $4 \mathrm{~mm}$ to $13 \mathrm{~m}$ and $8 \mathrm{~mm}$ to $26 \mathrm{~m}$.

The photographic information was acquired as described in $\mathbf{3 . 2}$ and memorized in a panorama consisting of the same number of pixels as the surveyed points, that is, for a scan at Super High 20,000 p x x 8,888 px resolution. The size of the GSD therefore corresponds to the geometric scan resolution.

A further check made during the planning phase relates to the dimension of the "beam diameter" (Bd), often referred to as "spot size", which grows in a linear manner from a value at or close to the emitter (Bi) as the distance (D) increases: (ASTM, 2011), (Tucci, 2013)

$\mathrm{Bd}=\mathrm{Bi}+($ divergence $* \mathrm{D})$

In the range of distances considered in the project it therefore assumed values varying from $7.5 \mathrm{~mm}$ to $13 \mathrm{~m}$ and $11.5 \mathrm{~mm}$ to $26 \mathrm{~m}$ according to datasheet (Zoller + Fröhlich, 2015). Comparison of these values with those previously indicated for the scan resolution revealed an oversampling deemed to be acceptable as the priority was considered to be to satisfy the photographic resolution requirements. The GSD resulting in the photos memorized together with the Super-High resolution scans is the minimum for the final requested scale of representation (1:50). Yet it is not totally satisfactory for the elements surveyed from distances greater than planned owing to contingent conditions.

\subsection{Generating orthoimages}

In the survey of the building elevations (at least in the very frequent case when it is not possible to make scans from higher positions) it is evident that the geometric resolution of the scans decreases from ground level towards the roofs.

As presented in 3.1, orthoimages can be produced by rendering an orthogonal view of the textured point model. The Geco Laboratory's previous workflow required the generation of orthoimages in Cyclone (Leica Geosystems, 2015), software which can save files as TIFs with the relative referencing information. In this software it is possible to specify the size of each image in pixels; the corresponding dimension of the GSD however cannot be checked analytically but only by enlarging the object on the screen. The generated orthoimage represents what is visualized on the screen.

Instead, to survey the elevations of the Baptistery the data were elaborated in JRC Reconstructor (Gexcel, 2014), in which an "orthographic camera" is created in correspondence to the defined viewpoint (obviously at infinity in the case of orthoimages) and plane of projection. Then, thanks to the "virtual scan" tool, it is possible to resample the scene and generate a new point cloud, structured in a "grid" mode, with respect to the identified lie (Sgrenzaroli 2007). The size of the orthoimage is specified both in the image space (pixel size) and in the object space (image $1 \mathrm{xh}$ ). To optimize the process, which substantially depends on the GPU, the orthoimage is generated bit by bit, and the pieces then slotted into the mosaic. In this case, there was no need for subsequent resampling to standardize the pixel size. (Figure 2)

The workflow was further optimized using the $\mathrm{R}^{3}$ module in which the geometric data are effectively rendered with a pointbased system, a well-known system initially developed to solve the issue of the interactive rendering of very large point-

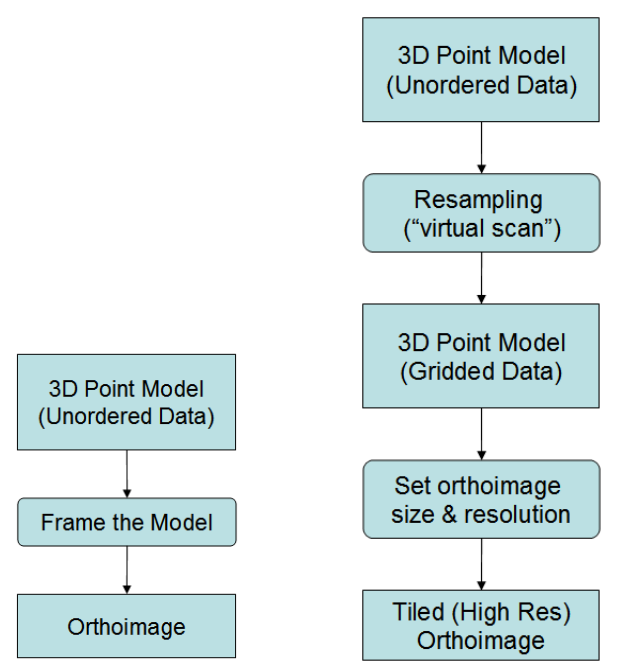

Figure 2. Ortoimage production workflow: Left - Cyclone (Leica Geosystems): low control on orthoimage resolution; Right - JRC Reconstructor (Gexcel): best orthoimage resolution, related to geometric resolution. 
data sets (for example for the Digital Michelangelo Project, see Rusinkiewicz, 2000). Each point is considered a "surfel": an element describing the surface in a small area. The rendering process discards points that are hidden from the current viewpoint and reconstructs continuous surfaces without holes from projected points.

In order to obtain better results, we rendered scan by scan, each of which previously cleared from undesired data. Then we balanced RGB channels to fix colour issues, and finally we blended all the partial orthoimages in the final one.

\section{DATA ACQUIS ITION}

In the first on-site survey phase, a topographic control network was defined, calculated and adjusted in a local reference system defined by the seven vertices of a traverse that surrounds and crosses the building.

To align the scans made outside, around 100 control points were measured, some to calculate alignments and others to check and validate the results. The choice was made to measure easily recognizable natural points (for example corners of the facing slabs), so as not to hide the surfaces with targets that would then be visible in the scans and partially hide the façades.

\begin{tabular}{|c|c|}
\hline Survey campaign & November - December 2013 (15 days) \\
\hline Staff used & $\begin{array}{c}4 \text { pax (topography)2 pax (scans) } \\
1 \text { pax (photographic campaign) }\end{array}$ \\
\hline Surveyed surface & $2,100 \mathrm{sq} \mathrm{m}$ \\
\hline $\begin{array}{c}\text { Control network } \\
\text { vertices }\end{array}$ & 7 \\
\hline $\begin{array}{c}\text { Stand } \\
\text { points/targets }\end{array}$ & 127 \\
\hline Accuracy & $< \pm 0.015 \mathrm{~m}$ \\
\hline No. scans & 275 (subcentimetric resolution) \\
\hline Points & 14.255 .787 .583 \\
\hline Hardware & $\begin{array}{c}\text { Leica TCR } 303 \text { total station } \\
\text { Leica TPS } 1200 \text { total station } \\
\text { Z+F IM AGER 5010C phase-shift } \\
\text { scanner } \\
\text { Leica HDS6000 phase-shift scanner } \\
\text { D700 - D90 reflex Nikon }\end{array}$ \\
\hline Software & $\begin{array}{c}\text { Star-Net (topography) } \\
\text { Z+F Laser Control (range map colour) } \\
\text { Leica Cyclone (range maps) } \\
\text { Microstation (vectorization) } \\
\text { Autocad (vectorization) } \\
\text { JRC Reconstructor and JRC R3 } \\
\text { (extraction orthoimages and displacement } \\
\text { maps) } \\
\text { MesLab (mesh modelling) } \\
\text { Adobe Photoshop (graphic editing) }\end{array}$ \\
\hline
\end{tabular}

Table 3. Work summary
Inside, some topographically measured targets were temporarily placed as control points. A first scan, referenced thanks to these, was used to align the other ones, acquired without targets, and then was deleted. For the top parts and the roof an additional 5 scans were made from ground level and 11 from surrounding buildings.

At the same time, RGB values were also acquired from the same scan points, as described above. The interior was surveyed using a Z+F 5010C scanner, and a Leica Geosystems HDS6000 scanner where the insufficient light would not have enabled the acquisition of RGB values. Two hundred and forty-one scans were made: 34 on the ground floor, 42 in the ladies' gallery, 55 in the attic, 94 in the stairs and 16 in the space between the extrados of the dome and the roof (the latter from specially assembled scaffolding). (Table 3 )

\section{THE NEW SURVEY: 2D AND 3D GRAPHICS}

The point model obtained after aligning the scans is made up of $14,255,787,583$ points. Deliverables were derived from this with the necessary level of detail for correct and effective reproduction on paper at a 1:50 scale (see Figure 4):

- Section profiles: a typical 2D architectural drawing is not obtained from a single section plan: to make four floor plans and four sections, 20 complete slices were made, as well as a lot more partial slices to define some more complex areas (undercuts, projecting parts, etc.);

- Elevations and visible elements of the sections, with orthoimages of the point cloud elaborated as described above (3.4);

- Surface models, restricted to some particular portions, such as one of the spiral staircases that link the ground floor to the ladies' gallery level and one of the elevations, of which a 3D print was also made.

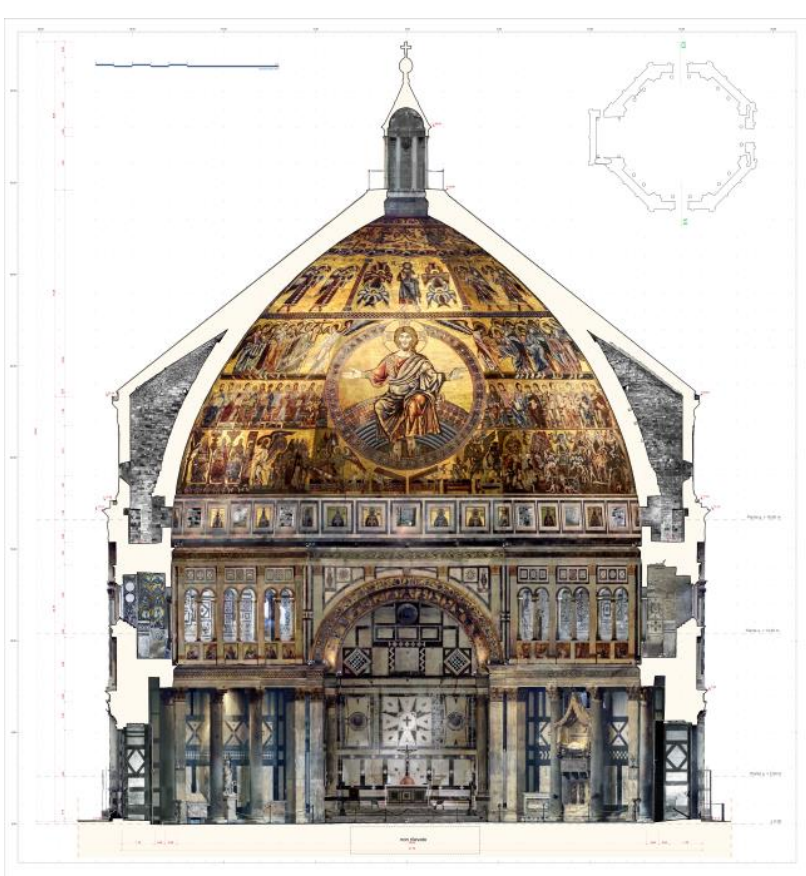

Figure 4. Longitudinal section: vectorial drawing and orthoimage 


\section{SOME EXAMPLES OF BUILDING INTERPPRETATION THROUGH THE DIGITAL S URVEY}

Thanks to the exhaustive and high-resolution survey data, not only the main dimensions of the building and its components could be documented, but also local irregularities. As a result, the construction and technological characteristics of the building could be examined.

\subsection{The vault extrados}

Among those spaces which have been subject to less investigation, the spaces between the vault, the outside wall of the Baptistery and the roof are particularly interesting. . Surveying extrados surfaces always involves notable operating difficulties linked to problematic access and movement in narrow spaces (Balletti, 2013). Since scaffolding was mounted, the extrados surface of the vault could be surveyed in four different positions; a 3D surface model was made of each portion investigated.

The wooden chain surrounding the whole dome was documented for each of the surveyed parts, at the height where masonry changes from stones to large bricks. In particular, the joint between the different elements, visible on the south-eastern side, was analysed. The models' high level of detail enabled documentation of the position of the putlog holes too. It was also possible to recognize the materials and structure of the brickwork and begin a statistical analy sis of the dimension of the bricks in order to verify hypothesized dating of the building. (Figure 5)

\subsection{Rampant vaults}

In the same way, the digital model enabled the formulation of some hypotheses on how the rampant vaults visible under the roof were built: the position of the putlog holes in the highest part of the radials walls, the irregular bed for the stone elements and their division into transversal strips lead to the hypothesis that the rampant vaults were built using earthen centerings progressively lifted upwards.

\subsection{Stairs}

Another area in which detailed knowledge of the space and construction details are of definite interest is the stairs.

Access to the levels of the ladies' gallery and attic is provided by two small spiral staircases either side of the Door of Paradise, built inside the pillars in the corners of the octagon. A surface model was made of the North staircase. This can be explored in real time in PDF3D format, by progressively moving a horizontal section plan to view the internal parts.

By looking at the model it is possible to examine the overall lay out of the openings - nonetheless these are very evident from the staircase. Some of them face outwards, and others inwards, but they are not visible as they are covered over by the marble facings. Their exact position with regard to the internal space gives rise to questions on what interventions may have modified the internal cladding, and in particular that of the pillars.

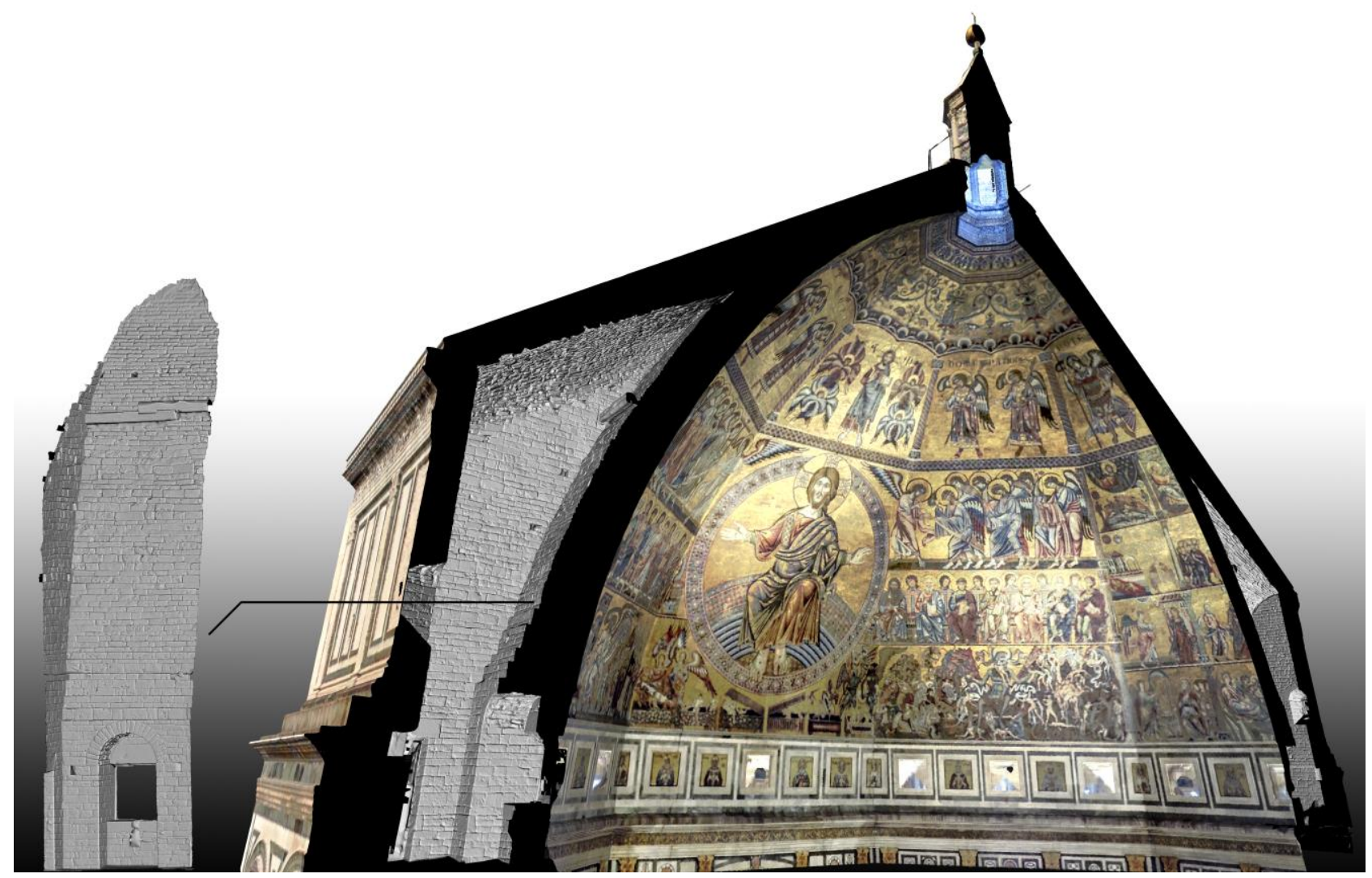

Figure 5. 3D section of the vault. 


\subsection{Deformations of the structure}

3D models can be the medium for viewing various kinds of phenomena: for example, remaining within the structural sphere, deformation of the walls was studied by displacement maps computed comparing them to vertical planes. The North, East and South walls were analysed (those with doors). This highlighted that on the outside they all bulge by around $5 \mathrm{~cm}$ between the second order and the attic level, right underneath the strip without marble cladding, with the metal chain laid inside in 1514. At the same height, the internal face of the brickwork presents a similar, albeit smaller bulge (Figure 6). The façades can also be seen to be out-of-plumb by a few centimetres towards the outside. This is not visible to the eye owing to the complex conformation of the elevation.

\subsection{Structural analysis with FEM}

Different geomatics technologies can be applied for structural monitoring (Castagnetti, 2016), but still ongoing research projects are focused on the optimization of procedures to use surface models in structural analysis software. (Castellazzi, 2015) In the present state, only simpler geometrical models to those obtained with the described methods can be used for FEM analyses. On one hand, this leads to a diseconomy, as new 3D models need to be made manually instead of using existent ones. On the other hand, it leads to less accuracy in terms of the real geometry and notable approximations. An assessment of the possible effects on the final results of the calculations of using the more accurate models provided by geomatic surveys is currently under study.

\section{FINAL REMARKS}

The paper refers to a specific case study to analyse the potentials and problems of photogrammetric and laser scanning systems. In particular, attention is focused on the possible use of both techniques to produce large-scale orthoimages which can support multidisciplinary analyses and conservation projects. The GeCo Laboratory has recently carried out various 3D surveys on real and complex case studies, including the glazed earthenware frieze at Ospedale del Ceppo in Pistoia (Tucci, 2015) and the Fortezza da Basso in Florence. On all these case studies, it was assessed beforehand whether to choose photogrammetric rather than laser scanning techniques.

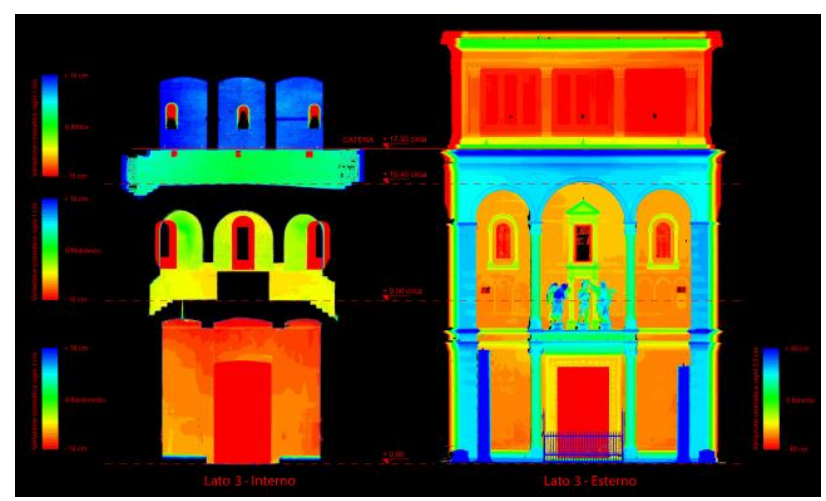

Figure 6. Deformation analysis on the East facade
A careful preliminary analysis of the specific situations and analy tical quantifications of the results on test areas resulted, in the case of the frieze, in a photogrammetric survey, and in the case of the Fortezza, in using both techniques.

At the Baptistery it was chosen to use scanning systems to also produce graphic output most often made from oriented images. The choice made limited as far as possible those operating difficulties resulting from the challenging lighting conditions, in particular inside (from almost total darkness to backlight from spotlights and irregular reflections from the mosaics). At the same time, it was possible to obtain a complete model of the building, the perimeter facings and the internal spaces which, except for the central area, in many cases are intricate and narrow. Thanks to the optimized workflow, for this case study it was also possible to limit the topographic operations, which are indispensable for referencing the survey data but, as is known, are demanding in terms of on-site logistics.

In conclusion, it can be considered that photogrammetry and laser scanning do not have to be thought of alternative techniques. As the graphic output is highly comparable, the optimal solution for each case requires careful consideration, which is strongly conditioned by the logistical and operating conditions.

The paper ends by illustrating how, thanks to the exhaustive 3D data recorded, the 3D model enabled the examination of elements of particular interest for the study of construction techniques and the static conditions of the structure. This provides a fundamental contribution to the multidisciplinary study campaign begun on the Baptistery on occasion of its restoration. Therefore, the purpose of the survey was not just to provide a reliable graphic output for studies and analyses by other specialists, but to play an active role in providing knowledge of the different components of the building (space, structure, technology, etc.) confronting each other with different methods of investigation to suggest and verify various hypotheses.

\section{REFERENCES}

Aminti P., 1996. Rilievo e determinazione della curvatura della cupola, analisi sui rapporti dimensionali tra principali elementi strutturali interni. In: S. Maria del Fiore. Piazza Battistero Campanile, Rocchi, G. (Eds), Florence, pp. 103-105:3.

ASTM, 2011. Standard Terminology for Three-Dimensional (3D) Imaging Sy stems, E2544 - 11a

Balletti, C., Berto, M., Gottardi, C., Guerra, F., 2013. Ancient structures and new technologies: survey and digital representation of the wooden dome of SS. Giovanni e Paolo in Venice. In: The International Annals of Photogrammetry, Remote Sensing and Spatial Information Science, Göttingen, Germany, Vol. II-5/W1, pp. 25-30

Balletti, C., Guerra, F., 2015. The survey of cultural heritage: a long story. In: Rendiconti Lincei, Vol. 26, pp. 115-125. DOI: 10.1007/s12210-015-0411-8 
Capra A., Bertacchini E., Castagnetti C., Rivola R., Dubbini M., 2015. Recent approach in Geodesy and Geomatiocs for structures monitoring. In: Rendiconti Lincei, Vol. 26, Issiue 1, pp.53-61, June 2015

Castellazzi, G., D'Altri, A. M., Bitelli, G., Selvaggi, I., Lambertini, A., 2015. From laser scanning to finite element analysis of complex buildings by using a semi-automatic procedure. Sensors, 15, pp. 18360 - 18380

Caroti, G., Fangi, G., 2004. Il rilievo della volta interna del Battistero. In: S. Maria del Fiore e le chiese fiorentine del Duecento e del Trecento nella città delle fabbriche arnolfiane, Rocchi, G. (Eds), Florence, pp. 145-148:4

Cignoni, P., Montani, C., Scopigno, R., Rocchini, C., 1998. A general method for preserving attribute values on simplified meshes. In: Proceedings of the conference on Visualization '98(VIS '98). IEEE Computer Society Press, Los Alamitos, CA, USA, pp.59-66.

Ferri, W., 2004. Rilievo fotogrammetrico della cupola del Battistero. In: S. Maria del Fiore e le chiese fiorentine del Duecento e del Trecento nella città delle fabbriche arnolfiane, Rocchi, G. (Eds), Florence, pp. 139-144:6

Fratini, M. , Pieraccini, M. , Betti, M. , Bartoli, G. , Atzeni, C. , 2011. Assessment of vibration reduction on the Baptistery of San Giovanni in Florence (Italy) after vehicular traffic block. In: Journal of Cultural Heritage, 12(3), pp. 323-328.

Gexcel 2014. JRC 3D Reconstructor-Operation manual. Available

online: http://www.gexcel.homeip.net/Reconstructor/R_Manual/ R_Manual_EN.pdf

Guarnieri, A., Remondino, F., Vettore, A., 2006. Digital photogrammetry and TLS data fusion applied to Cultural Heritage 3d modelling. In: The International Archives of Photogrammetry, Remote Sensing and Spatial Information Sciences, Dresden, Germany, Vol. XXXVI, Part 5.

Jauregui, M., Vilchez, J., Chacon, L., 2000. Digital orthophoto generation. In: The International Archives of Photogrammetry, Remote Sensing and Spatial Information Sciences, Amsterdam, Vol. XXXIII, Part B4, pp. 400-407.

Leica Geosystems, 2015, Cyclone Technical specifications. Available on line: http:/hds.leicageosy stems.com/downloads 123/hds/hds/cy clone/brochuresdatasheet/Cyclone_Technical_Specification_en.pdf

Ranzuglia, G., Callieri, M., Dellepiane, M., Cignoni, P., Scopigno, R., 2013. MeshLab as a complete tool for the integration of photos and color with high resolution $3 \mathrm{D}$ geometry data. In: CAA2012 Proceedings of the 40th Conference in Computer Applications and Quantitative Methods in
Archaeology, Southampton, United Kingdom, 26-30 March 2012, pp. 406-416

Remondino F., Fraser, C., 2006. Digital camera calibration methods: considerations and comparisons. In: The International Archives of Photogrammetry, Remote Sensing and Spatial Information Sciences, Dresden, Germany,Vol. XXXVI, Part 5, pp.266-272

Sabatini, R., 1943. La curvatura e la costruzione della cupola del battistero. In: Palladio, V-VI, pp. 159-163

Sgrenzaroli, M., Vassena G. P. M., 2007. Tecniche di rilevamento tridimensionale tramite laser scanner., Starrylink Editrice, Brescia, ISBN: 978-88-89720-73-8

Szeliski, R., 2011. Computer Vision: Algorithms and Applications, Springer.

Rusinkiewicz, S., Levoy, M., 2000. QSplat: A multiresolution point rendering system for large meshes. In: Proceedings of SIGGRAPH 2000 - $27^{\text {th }}$ annual conference on Computer graphics and interactive techniques, pp.343-352.

Tucci, G., Bonora, V., Guardini, N., 2013. Analyses of the factors affecting 3D models resolution-application to the recording of vaults in Sangallo's house. In: The International Annals of Photogrammetry, Remote Sensing and Spatial Information Science, Strasbourg, France, Vol. II-5/W1, pp. 307312.

Tucci, G., Bonora, V., Conti, A., Fiorini, L., 2015. Benchmarking Range-Based and Image-Based Techniques for Digitizing a Glazed Earthenware Frieze. In: The International Annals of Photogrammetry, Remote Sensing and Spatial Information Science, Taipei, Taiwan, Vol. II-5/W3, pp. 315-322.

Zoller + Fröhlich, 2015. Z+F IM AGER 5010C Techincal sheet. Available on line: http://www.zflaser.com/fileadmin/editor/Datenblaetter/Z_F_IMAGER_5010C _Datasheet_E.pdf 